\title{
MODEL TRANSPORT STUDIES UTILIZING LECITHIN SPHERULES
}

\section{CRITICAL EVALLATIONS OF SEVERAL PHYSICAL MODELS IN THE DETERMINATION OF THE PERMEABILITY COEFFICIENT FOR GLLCOSE}

\author{
ZAKA-UD-DIN T. CHOWHAN, TOSHIHISA YOTSUYANAGI AND WILLIAM I. HIGUCHI
} College of Pharmacy, University of Michigan, Ann Arbor, Mich. 48 I04 (U.S.A.)

(Received November IIth, 1971)

SUMMARY

I. For the purpose of quantifying the transport of drugs across phospholipid membranes in complex aqueous liposome dispersions, solute release experiments were conducted with different initial boundary conditions so that sensitive tests of appropriate physical models could be made.

2. Simple physical models which assume monosize or multisize single membrane controlled solute transport failed to provide a reasonable agreement between the experimental data and the theory.

3. A systematic evaluation of all the parameters which could introduce uncertainties then revealed that the monosize-multiconcentric models are generally in satisfactory agreement with the experimental transport data. These findings suggest that these models may be used in the reliable determinations of effective bulk permeability coefficients. Calculations using the multisize-multiconcentric models and comparisons between the monosize and multisize-multiconcentric models showed that the assumption in which the particle size distribution is neglected is a good one.

\section{INTRODUCTION}

Detailed knowledge of the various components and their organization in the cell membranes would be very important in the understanding of the many factors involved in the movement of molecules and ions across biological membranes. However, the uncertainty of what constitutes a cell membrane, the lack of knowledge about the various components of these membranes and the large number of different components thought to be present in a cell membrane, all introduce an enormous degree of complexity into the problem. Notwithstanding the many difficulties, fruitful progress has been made in recent years by the development of several model membrane systems based on the Danielli-Davson ${ }^{1}$ bimolecular leaflet model and its latter modification into the unit membrane hypothesis by Robertson ${ }^{2}$. These model systems have been used to correlate one or another property of the natural membrane with the behavior of pure membrane lipids, since such lipids have been found to be an 
invariant component of all cell membranes examined thus far, accounting for at least $25 \%$ of the total dry weight ${ }^{3}$.

One of these model systems has been used quite extensively for solute transport studies by several workers since its original development by Bangham et al. ${ }^{4}$ and utilizes liposome dispersions. This model system is based on the evidence derived from electron microscopy ${ }^{5,6}, \mathrm{X}$-ray diffraction ${ }^{7-9}$ and optical birefringence ${ }^{10}$, which indicates that when naturally occurring phospholipids are equilibrated with aqueous solutions, they form liquid crystals of smectic-mesophase type composed of bimolecular lamella separated by aqueous compartments. The degree of swelling, size, shape and general configuration of the resulting liquid crystals depend on the particular phospholipid used, as well as on the ionic strength, the valency of the ionic species present and the $\mathrm{pH}$ of the medium ${ }^{11}$.

Combination of the differences in the self diffusion rates of anions and cations and the accompanying osmotic sensitivity has suggested similarities in the behavior of liposome dispersions and the biological membranes. There is little doubt that the liposome dispersion model membrane system is of considerable interest and that it can be used as Bangham and several other workers have shown in the investigations that are relevant to the actions of polyene antibiotics ${ }^{12-15}$, ion discriminating antibiotics, valinomycin ${ }^{16,17}$, gramicidin ${ }^{17}$, steroids ${ }^{18,19}$, narcotics ${ }^{20}$, anaesthetics ${ }^{21}$, local anaesthetics ${ }^{22}$, surfactants ${ }^{23}, 24, \mathrm{Ca}^{2+}$ (refs $\left.17,22,25\right)$ and $\mathrm{Mg}^{2+}$ (ref. 25) on biological membranes.

However, most of these studies have been of qualitative nature due to the complexity of the dispersion system, and realizing the limitations of such studies, Johnson and Bangham ${ }^{18}$ made an attempt to develop a quantitative method for determining the permeability coefficients of a single bilayer. By prolonged sonication of a dispersion system, these investigators attempted to produce a dispersion which consisted mainly of single bilayer liposomes. The $\mathrm{K}^{+}$release data obtained with this system were analyzed by means of a first order mathematical relationship which was expected to be applicable to a monodispersed, single bilayer dispersion system. When attempts were made to analyze the experimental data by the equation, significant deviations were always observed and this precluded the meaningful determination of permeability coefficients. The marked deviations from theory were partly attributed to the size distribution of the bilayer dispersion and the multiconcentric layer nature of some of the liposomes in the system.

The present study deals with the development and evaluation of a method which would allow the reliable determination of permeability coefficients in the liposome dispersion model membrane system. The experimental procedure is relatively straightforward and should be applicable to the study of the transport behavior of a variety of solutes in these systems.

EXPERIMENTAL

\section{General considerations}

The requirements to fulfill the objectives of the present study may be outlined in the following:

(i) The preparation of nonaggregating spherical liposomes. 
(ii) The control of size and shape of the liposomes during the preparation procedure and not by mechanical shaking or sonication after the formation.

(iii) A reliable method for the determination of particle size distribution.

(iv) Good sensitivity of the method to permeability coefficients.

(v) Reliability and precision in the transport rate data.

(vi) Availability of rigorous theoretical procedures for the analysis of the experimental data including the selection of the best physical model and the determination of the physical chemical parameters.

Several methods of preparing a liposome dispersion were considered. Since egg yolk lecithin swells spontaneously when brought in contact with aqueous solution, the method of adding an aqueous solution to a thin coating of lecithin on glass surface produced aggregates and shape problems. All attempts to deaggregate the particles and improve the shape problems by mechanical shaking or sonication proved unsuccessful. The method of making liposome dispersions by mixing the aqueous and chloroform solution was then tried. First, a dispersion of lecithin in a chloroformaqueous solution mixture was formed under vacuum of a water aspirator. Then, the chloroform was removed slowly. This method produced spherical liposomes which were free from aggregates.

It was decided to conduct solute release experiments with different initial boundary conditions so that sensitive tests of appropriate models could be made. Three initial boundary conditions were selected for this purpose. The first ("directrelease" experiment) was solute release from the dispersion in which the solute was fully equilibrated between the spherule interior and the external aqueous phase. In the second situation ("dilution-release" experiment) the dispersion was diluted by about a factor of ten just prior to the beginning of the release run. In the third case, ("uptake-release" experiment) the dispersion was first prepared without the radioactive solute. Then the spherules were allowed to absorb the radioactive solute for a predetermined period of time just before the release run. As will be seen these three procedures, in conjunction with the theoretical analysis help significantly in both the selection of the best model and the determination of the best set of values for the parameters.

\section{Materials}

The egg yolk lecithin was prepared by the method ${ }^{25}$ which is based on the procedure developed by Rhodes and $\mathrm{Lea}^{27}$ was stored under $\mathrm{N}_{2}$ at $-20{ }^{\circ} \mathrm{C}$. The alumina suitable for chromatography (obtained from Matheson Coleman and Bell, Norwood, Ohio, U.S.A.) was activated by drying at $\mathrm{I}$ Io ${ }^{\circ} \mathrm{C}$ overnight. Silicic acid especially prepared by the method of Hirsh and Arhens ${ }^{28}$ (obtained from Bio-Rad Laboratories, Richmond, Calif., U.S.A.) was used. Purity checks were made by thin-layer chromatography on Eastman Chromatogram sheets, 606o Silica Gel (Eastman Kodak Company, Rochester, N.Y., U.S.A.). Lecithin samples in chloroform solution were applied to the chromatogram sheets and the sheets were developed by the solvent system chloroform-methanol-water $\left(65: 25: 4\right.$, by vol.) in a saturated chamber ${ }^{29}$. Chromatographs for the detection of nonphosphorous containing compound were developed by the solvent system, light petroleum-diethyl ether (90: 10, by vol. $)^{30}$ also in a saturated chamber. Iodine vapors were used for non specific detection of chromatographed materials ${ }^{31}$. Ninhydrin and Dragendorff reagents were used for 
the confirmation of amine and choline compounds respectively. Dicetyl phosphate (obtained from Sigma Chemical Company, Mo., U.S.A.) was used without further purification. Anhydrous D-glucose (obtained from J. T. Baker Chemical Co., Phillipsburg, N.J., U.S.A.) was reagent grade and $\mathrm{D}-\left[\mathrm{I}^{-18} \mathrm{C}\right]$ glucose was obtained from New England Nuclear, Boston, Mass., U.S.A. in crystalline solid form at specific activity of $7.08 \mathrm{mCi} / \mathrm{mmole}$.

\section{Apparatus}

Fig. I shows a schematic diagram of the apparatus used for the solute transport studies. The set-up consisted of a water jacketed beaker and a dialysis bag holder stirring assembly. The temperature of the system was controlled by circulating water at $25{ }^{\circ} \mathrm{C}$. A I $50 \mathrm{rev} . / \mathrm{min}$ synchronous motor and the dialysis bag holder are mounted on a polyethylene cover plate. The dialysis bag holder consisted of two $\mathrm{I} / \mathrm{I} 6$ inch gauge stainless steel wire which formed a square framework for the dialysis bag. The stirrer was made from plexiglass. Two holes were drilled in the polyethylene coverplate, one for the stirrer and the other for holding the thread which tied the dialysis bag (obtained from Union Carbide Corporation, Chicago, Ill. U.S.A.) at the lower end. The beaker contained Ioo $\mathrm{ml}$ of sink solution which was stirred by a $3 / 16$ inch $\times 7 / 8$ inch long teflon magnetic stirring bar by means of another synchronous motor at $150 \mathrm{rev} . / \mathrm{min}$ placed at the bottom of the beaker.

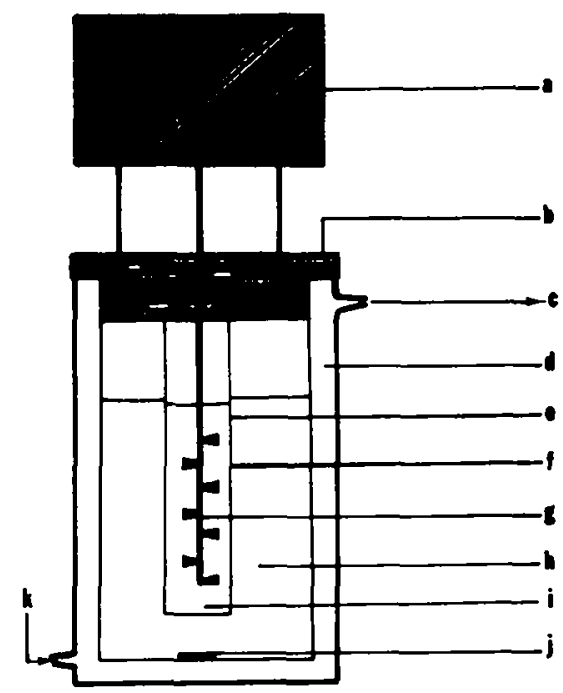

Fig. I. Apparatus used for solute transport release studies. a, synchronous motor; $b$, polyethylene cover; $c$, water outlet; $d$, jacketed beaker; e, dialysis bag holding framework; $f$, dialysis bag; $g$, stirrer; $h$, sink; $i$, dispersion; $j$, stirring bar; $k$, water inlet.

In the design of this apparatus the following points were considered important:

(i) The higher the surface area to volume ratio of the bag exposed to the sink, the more sensitive would be the system to the determination of permeability coefficient.

(ii) Moderate stirring inside the bag and in the sink solution would minimize diffusion layer build up around the bag. 
(iii) Complete replacement of the sink solution at each sampling time would provide semi-infinite sink conditions and would allow a better precision in the determination of transport rates.

\section{Procedures}

The following procedure was used for the preparation of the dispersions used in the release transport studies. An appropriate volume of a $15 \%$ chloroform solution of lecithin with added dicetyl phosphate was added to a $250 \mathrm{ml}$ round bottomed flask. Then a required volume of $5.14 \%$ glucose solution containing radioactive glucose was added. A $3 / 8$ inch $\times 1 / 2$ inch long/teflon magnetic stirring bar was dropped into the flask and the flask attached to a flash evaporator. The aqueous and the nonaqueous solutions were allowed to mix under magnetic stirring and rotary motion of the flask for one hour under low vacuum obtained by using a water aspirator at room temperature. At the end of this period, the stirring and the rotary motion was reduced and the chloroform removed slowly by increasing vacuum with a controlled leak to prevent frothing. The size distribution of the lecithin spherules was controlled by the amount of stirring used at this stage; for example, low speed stirring produced a wider distribution and much larger size spherules and moderate speed stirring produced a narrow size distribution. After complete removal of the chloroform, the dispersion was checked under the microscope and, if the procedure was followed carefully, the microscopic examination did indicate that the dispersion system indeed consisted of nonaggregated spherical liposomes. The dispersion was then allowed to equilibrate for $3 \mathrm{~h}$ under magnetic stirring at $150 \mathrm{rev}$./ $\mathrm{min}$ before the start of the release experiment.

For the uptake-release transport experiments, the dispersions were prepared using the same procedure as outlined above with the difference being that the glucose solution added at the time of preparation contained no radioactive glucose. The radioactive solute was then added to the external phase after the preparation of dispersion and the release experiment was started after a predetermined period of radioactive solute uptake by the spherules.

In the direct-release, dilution-release and in the uptake-release experiments, $5 \mathrm{ml}$ of the dispersion was added to the dialysis bag and at zero time the dialysis bag stirring assembly placed in a water-jacketed beaker containing $100 \mathrm{ml}$ sink solution and the stirrer started. At the end of each sampling time the dialysis bag stirring assembly was transferred to another water-jacketed beaker containing Ioo $\mathrm{ml}$ of fresh sink solution. I-ml samples were withdrawn from the sink solution and added to the liquid scintillation vial. To the latter, Io $\mathrm{ml}$ of a liquid-scintillation cocktail was added. (I'or Liquid-Scintillation Cocktail composition see ref. 32) Radioactive counts were measured by Beckman liquid scintillation system (Beckman Instruments, Inc., Fullerton, Calif., U.S.A.).

The particle size distribution of the dispersion was determined by the Coulter Counter (Model A, Coulter Electronics, Hialeah, Fla., L.S.A.) on aliquots taken after the start of the transport experiments. From the particle size distribution, mean surface, mean volume radius and total volume of the dispersed phase were calculated. Microscopic determinations of the particle sizes were always found to be in good agreement with the Coulter Counter results. 
RESULTS

The three different initial boundary conditions; the direct-release, the dilutionrelease and the uptake-release situations were investigated. In order to check the reproducibility of the method, experiments were repeated using the same batch or different batches of purified egg yolk lecithin. Experiments were also repeated using commercial L- $x$-Lecithin (egg) (chromatographically pure) (obtained from General Biochemicals, Laboratory Park, Chagrin Falls, Ohio, U.S.A.). The first initial boundary conditions represented a typical direct-release experiment, in which the transport of isotopic $\mathrm{D}$-glucose into the sink was studied as a function of time. The experimental results of the direct-release experiment are given in Fig. 2. The results of the dilutionrelease experiment and the uptake-release experiments are given in Fig. 3 and 4

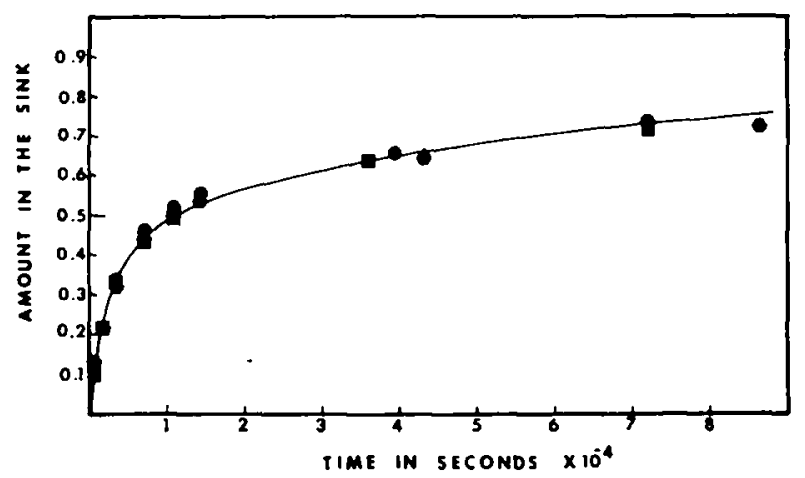

Fig. 2. Data showing release of $\mathrm{D}$-glucose as a function of time from a $5 \%$ lecithin $-0.5 \%$ dicetyl phosphate dispersion system. Symbols represent experimental data; triangles, dispersion system $\mathrm{I}$, prepared from lecithin batch $\mathrm{r}$; hexagonals, dispersion system 2 , prepared from lecithin batch I; squares, dispersion system 3, prepared from lecithin batch 2 ; circles, dispersion system 4, prepared from commercial lecithin; curve represents calculations using Eqns 11,16 to 18 and the parameter values given in Table II. Ordinate represents $A_{\mathrm{y}}$, normalized amount of solute in the sink.

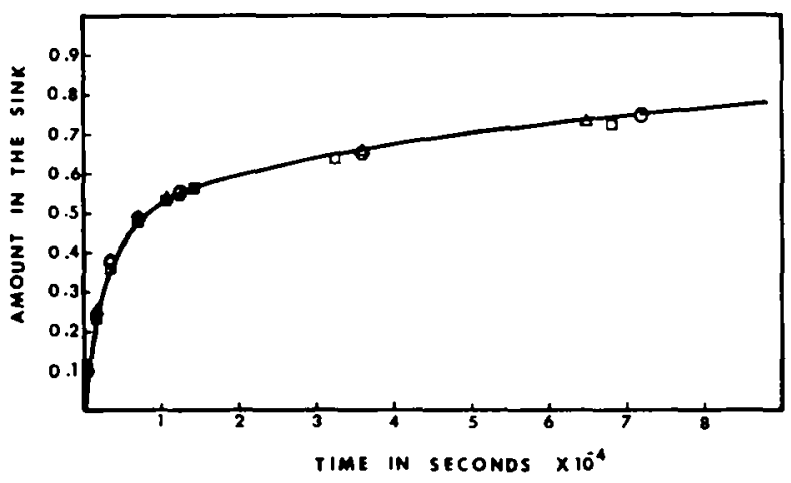

Fig. 3. Results from the dilution-release experiments showing the release of $D$-glucose as a function of time from a lecithin-dicetyl phosphate dispersion system. Symbols represent experimental data. Triangles, dispersion system prepared from lecithin batch $x$; squares, dispersion system prepared from lecithin batch 2 ; circles, dispersion system 3, prepared from commercial lecithin; hexagonals, dispersion system 4 , prepared from commercial lecithin; curve represents theoretical calculations using Eqn II, and Eqns 16 to 18 ; the parameter values given in Table II. 
respectively. In the latter experiments uptake periods of $0,2,10$, and $24 \mathrm{~h}$ preceded the release run.

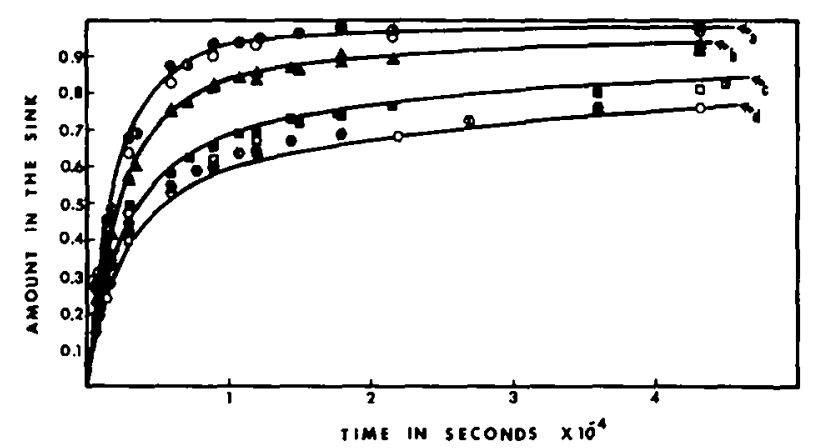

Fig. 4. Results from the uptake-release experiments showing release of D-glucose as a function of time from lecithin-dicetyl phosphate dispersion system. Symbols represent experimental data; after $\mathrm{o}-\mathrm{h}$ solute uptake: circles with line, dispersion system I, prepared from lecithin batch I; closed circles, dispersion system 2, prepared from lecithin batch 2 ; open circles, dispersion system 3, prepared from commercial lecithin; after 2 -h solute uptake: triangles with line, dispersion system I, prepared from lecithin batch I; closed triangles, dispersion system 2, prepared from lecithin batch 2; open triangles, dispersion system 3, prepared from commercial lecithin; after Io-h solute uptake: squares with line, dispersion system $I$, prepared from lecithin batch 1 ; closed squares, dispersion system 2, prepared from lecithin batch 2 ; open squares, dispersion system 3 . prepared from commercial lecithin; after $24^{-h}$ solute uptake: hexagonals with line, dispersion system I, prepared from lecithin batch I; closed hexagonals, dispersion system 2, prepared from lecithin batch 2 ; open hexagonals, dispersion system 3, prepared from commercial lecithin. Curves a, b, c and d represent theoretical calculations using Eqns $I I$ and $I 6$ to $I 8$ and the parameter values given in Table II, after $0-, 2-$, IO- and 24 -h solute uptake, respectively.

In all experiments the reproducibility of the results using the same batch of chromatographically pure egg yolk lecithin was extremely good. However, some batch to batch variation may be noted.

Typical Coulter Counter particle size distribution data are given in Table I. Some variations in the particle size distribution for different batches was found. This was expected due to the complex nature of the dispersion system. In spite of these variations, the calculated volume, mean surface and mean volume radii of the dispersed phase showed good batch to batch reproducibility.

\section{THEORETICAL ANALYSIS OF THE RESUITS}

Due to the complexity of the liposome dispersion model membrane system most of the previous studies pertaining to the solute transport were qualitative. Johnson and Bangham ${ }^{16}$ recently reported a method which permitted them to determine permeability coefficients of $\mathrm{K}^{+}$in highly sonified dispersions of $4 \%$ phosphatidic acid-phosphatidyl choline. It was believed that the liposomes consisted of single bilayers separating aqueous compartments. In the treatment of the data, the amount of solute released from inside of the liposomes during sephadex column treatment and before the start of the transport release run were neglected. Also, the permeability of solute through the bag was considered extremely fast compared to the permeability through the liposomes and was therefore neglected. The comparison of experimental data with theory revealed marked deviations after initial times. These findings indi- 
TABLE I

THE PARTICLE SIZE DISTRIBUTION OF LECITHIN-DICETYL PHOSPHATE DISPERSION SYSTEM AND ITS CALCULATED PARAMETERS

\begin{tabular}{|c|c|c|c|c|c|}
\hline \multirow[t]{2}{*}{ Element } & \multirow{2}{*}{$\begin{array}{l}\text { Radius } \\
(\mu \mathrm{m})\end{array}$} & \multicolumn{2}{|l|}{ Batch I } & \multicolumn{2}{|l|}{ Batch 2} \\
\hline & & $\begin{array}{l}\text { Total No. } \\
\times \quad O^{-10}\end{array}$ & $\begin{array}{l}\text { Total volume } \\
\left(\mu \mathrm{m}^{3}\right) \times 10^{-10}\end{array}$ & $\begin{array}{l}\text { Total No. } \\
\times 10^{-10}\end{array}$ & $\begin{array}{l}\text { Total volume } \\
\left(\mu \mathrm{m}^{3}\right) \times I 0^{-10}\end{array}$ \\
\hline I & 0.52080 & 5.4288 & 3.2124 & 4.8008 & 2.8396 \\
\hline 2 & $0.656 \mathrm{r}_{7}$ & 4.9948 & 5.93228 & $6.014^{8}$ & 7.1188 \\
\hline 3 & 0.77797 & 1.0124 & I.99704 & I.0960 & I. 3728 \\
\hline 4 & 0.87031 & 0.3856 & 1.06488 & 0.4464 & I. 2328 \\
\hline 5 & 0.94636 & 0.2372 & 0.84220 & $0.443^{2}$ & $1.573^{6}$ \\
\hline 6 & I.OII 8 & 0.2476 & I. I $744^{8}$ & $0.324^{\circ}$ & I. 4060 \\
\hline 7 & I . I 464 & 0.2792 & I. 76240 & 0.3144 & I. 9844 \\
\hline 8 & I. $3 \circ 3$ & 0.0784 & 0.77324 & 0.0964 & 1.9508 \\
\hline 19 & 1.4882 & 0.0404 & 0.53784 & $0.025^{2}$ & $0.34^{8}$ \\
\hline ro & 1.6183 & 0.0256 & 0.45448 & 0.0092 & 0.1632 \\
\hline I I & 1.7302 & 0.01800 & 0.39056 & 0.0080 & o. 1696 \\
\hline I 2 & 1.8293 & 0.01280 & 0.32824 & $0.005^{2}$ & o.I 332 \\
\hline I3 & I.9I 86 & 0.0088 & 0.26038 & 0.0084 & 0.2484 \\
\hline I 4 & 2.0004 & $0.006_{4}$ & 0.26827 & 0.0048 & 0.1608 \\
\hline I 5 & 0.0759 & 0.0040 & 0.23987 & 0.0024 & 0.0980 \\
\hline 16 & 2.1464 & 0.0044 & 0.16569 & 0.008 & 0.0328 \\
\hline I 7 & 2.2125 & 0.0040 & 0.19963 & 0.008 & 0.0364 \\
\hline 18 & 2.2748 & 0.0040 & 0.19724 & 0.008 & 0.0424 \\
\hline 29 & 2.3339 & 0.0028 & $0.2 I_{504}$ & 0.004 & 0.0228 \\
\hline 20 & 2.3902 & 0.0020 & 0.16016 & & \\
\hline $2 \mathrm{I}$ & 2.4439 & 0.0020 & 0.12228 & & \\
\hline 22 & 2.4954 & 0.0012 & o.1 30188 & & \\
\hline 23 & 2.5448 & 0.0012 & $0.0828_{4}$ & & \\
\hline 24 & 2.5924 & 0.0008 & 0.08760 & & \\
\hline 25 & $2.63^{8} 3$ & 0.0008 & 0.061 I 6 & & \\
\hline 26 & 2.6826 & 0.0008 & $0.0647^{2}$ & & \\
\hline 27 & 2.7256 & 0.0008 & 0.06744 & & \\
\hline 28 & $2.7^{6} 7^{2}$ & 0.0008 & $0.07 \mathrm{I} 00$ & & \\
\hline 29 & 2.8076 & 0.0004 & 0.03718 & & \\
\hline \multirow[t]{5}{*}{30} & 2.8468 & 0.0004 & $0.03^{864}$ & & \\
\hline & & & Batch $I$ & Batch 2 & \\
\hline & \multirow{2}{*}{\multicolumn{2}{|c|}{$\begin{array}{l}\text { Mean surface radius }(\mu \mathrm{m}) \\
\text { Mean volume radius }(\mu \mathrm{m})\end{array}$}} & 0.68504 & 0.68602 & \\
\hline & & & 0.72048 & 0.71373 & \\
\hline & Volume $_{\mathrm{I}}$ & , & 1.05 & 1.03 & \\
\hline
\end{tabular}

cate serious limitations of the method of Johnson and Bangham ${ }^{16}$ in the determination of permeability coefficients.

It is feasible to solve the rate equations using numerical methods without making many of the approximations. Therefore, it was decided to construct several physical models starting from the simplest. A systematic analysis of these models was then expected to permit the selection of the most suitable model for reliable determinations of permeability coefficients.

\section{The determination of experimental bag constant}

In the experimental arrangement, the overall transport of solute into the sink involves both the movement of solute out of spherules and the transfer of the solute 
across the dialysis bag. Therefore, it is important to consider the solute transport through the bag in the analysis of the data. The rate at which solute leaves the bag is given by Eqn $\mathbf{I}$.

$$
-V_{\mathrm{b}} \cdot \frac{\mathrm{d} C_{\mathrm{b}}}{\mathrm{d} t}=S_{\mathrm{b}} \cdot p_{\mathrm{b}} \cdot C_{\mathrm{b}}
$$

Here, $V_{\mathrm{b}}, C_{\mathrm{b}}$ and $S_{\mathrm{b}}$ are the volume of the solution or volume of the dispersion in the dialysis bag, the concentration of solute in the bag, the surface area of the bag, and $p_{0}$ is the effective permeability coefficient of the bag.

Integration of Eqn I from initial time $t_{0}$, when initial solute concentration is $C_{0}$ to an assigned time $t$, when the solute concentration is $C$, would lead to Eqn 2

$$
\ln \frac{C}{C_{0}}=-\frac{S_{\mathrm{b}}}{V_{\mathrm{b}}} \cdot p_{\mathrm{b}} \cdot t
$$

The relationship of concentrations in terms of amounts is given by Eqn 3 .

$$
\begin{gathered}
C=\frac{\left(A_{\mathrm{b}}\right)_{t=t}}{V_{\mathrm{b}}} \\
C_{0}=\frac{\left(A_{\mathrm{b}}\right)_{t=0}}{V_{\mathrm{b}}}
\end{gathered}
$$

Here $A_{\mathrm{b}}$ is the normalized amount of solute in the dialysis bag. Substituting Eqn 3 in Eqn 2 would give Eqn 4 .

$$
\ln \frac{\left(A_{\mathrm{b}}\right)_{t=t}}{\left(A_{\mathrm{b}}\right)_{t=0}}=-\frac{S_{\mathrm{b}} \cdot p_{\mathrm{b}}}{V_{\mathrm{b}}} \cdot t
$$

If the amount of solute in the pores of the bag is neglected, the total amount of solute is given by Eqn 5 .

$$
\left(A_{\mathrm{b}}\right)_{t=0}=\left(A_{\mathrm{b}}\right)_{t=\mathrm{t}}+\left(A_{\mathrm{s}}\right)_{t=t}
$$

Here, $A_{\mathrm{B}}$ is the normalized amount of solute in the sink.

Substituting $\left(A_{\mathrm{b}}\right)_{t=t}$ from Eqn 5 in Eqn 4 , Eqn 6 is obtained.

$$
\ln \frac{\left(A_{\mathrm{b}}\right)_{t=0}-\left(A_{\mathrm{s}}\right)_{t=t}}{\left(A_{\mathrm{b}}\right)_{t=0}}=-\frac{S_{\mathrm{b}} \cdot p_{\mathrm{b}}}{V_{\mathrm{b}}} \cdot t
$$

A plot of the log term in Eqn 6 vs time is shown in Fig. 5. A straight line was drawn through a set of four experimental points. The slope of the straight line represented $S_{\mathrm{b}} \cdot p_{\mathrm{b}} / V_{\mathrm{b}}$, from which the experimental bag constant was obtained. The latter was defined as the product of the permeability coefficient and surface area of the bag.

\section{Monosize single membrane model}

The spherules are assumed to be of the same size. Furthermore, the model assumes that the solute instantaneously partitions between the aqueous and the 
lipid phases within Compartment I, which represents spherules and that the only barrier to solute transport is located at the external lipid-aqueous interface.

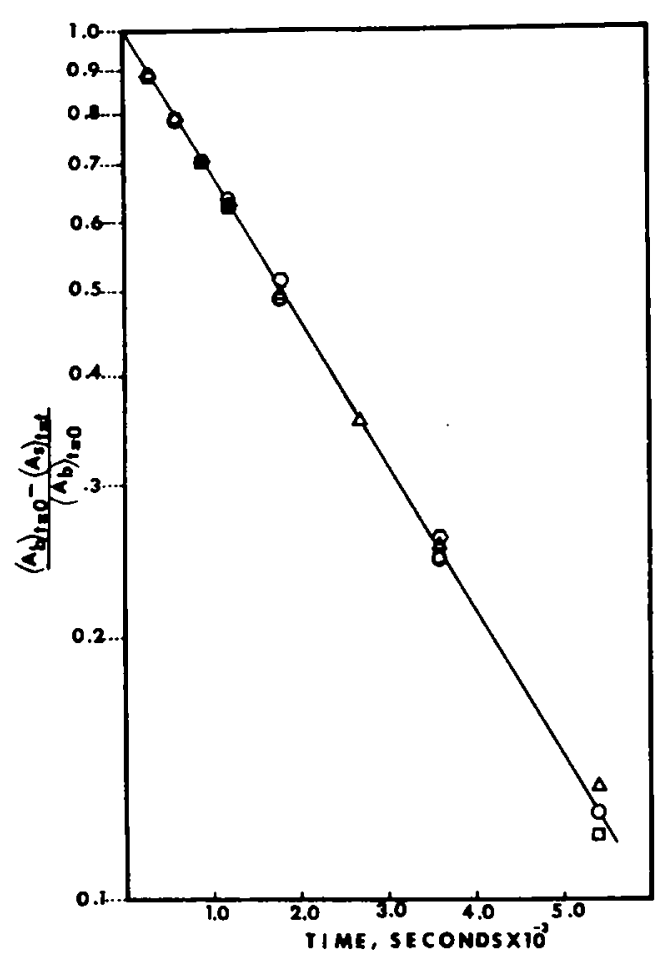

Fig. 5. First order plots used for the determination of bag constant of D-glucose through dialysis bag. Different symbols represent data from four experiments.

The relationship between the aqueous concentration and the total concentration in Compartment $\mathrm{I}$ is given by Eqn 7 .

$$
C_{\mathrm{I}, t}=\frac{V_{\mathrm{l}}\left(v_{\mathrm{a}}+k \cdot v_{l}\right)}{V_{\mathrm{I}}\left(v_{\mathrm{a}}+v_{l}\right)} \cdot C_{\mathrm{I}, \mathrm{a}}
$$

Here, $C_{\mathrm{I}, t}, C_{\mathrm{I}, \mathrm{a}}$ are the average and aqueous solute concentrations in Compartment $\mathrm{I}$, respectively; $v_{\mathrm{a}}$ and $v_{1}$ are the aqueous and lipid volume fractions of Compartment $\mathrm{I}$, respectively; $k$ is the lipid-aqueous partition coefficient.

The transport rate at which solute leaves Compartment $\mathrm{I}$ is given by Eqn 8 .

$$
-V_{\mathrm{I}} \cdot \frac{\mathrm{d} C_{\mathrm{l}, t}}{\mathrm{~d} t}=S_{\mathrm{I}} \cdot p\left(C_{\mathrm{I}, \mathrm{a}}-C_{\mathrm{II}}\right)
$$

Substituting $C_{\mathrm{I}, \mathrm{a}}$ for $C_{\mathrm{I}, t}$ from Eqn 7 in Eqn 8 and rearranging gives Eqn 9 .

$$
-\frac{\mathrm{d} C_{\mathrm{I}, \mathrm{a}}}{\mathrm{d} t}=\frac{S_{\mathrm{I}} \cdot p\left(C_{\mathrm{l}, \mathrm{a}}-C_{\mathrm{II}}\right)}{V_{\mathrm{l}}\left(v_{\mathrm{a}}+k \cdot v_{l}\right)}
$$


Here, $S_{I}$ and $p$ are the surface area and permeability coefficient of the spherules, respectively. The rate expression for solute concentration in Compartment II, the aqueous external phase of the liposome dispersion is given by

$$
V_{\mathrm{II}} \cdot \frac{\mathrm{d} C_{\mathrm{II}}}{\mathrm{d} t}=S_{\mathrm{I}} \cdot p\left(C_{\mathrm{I}, \mathrm{a}}-C_{\mathrm{II}}\right)-p_{\mathrm{b}} \cdot S_{\mathrm{b}} \cdot C_{\mathrm{II}}
$$

The rate of appearance of the solute in the sink is given by Eqn II.

$$
\frac{\mathrm{d} A_{\mathrm{s}}}{\mathrm{d} t}=p_{\mathrm{b}} \cdot S_{\mathrm{b}} \cdot C_{\mathrm{II}}
$$

These equations may be solved by numerical methods. The calculations were carried out using the IBM 360 digital computer. The computer flow diagram for the calculation of concentration and amount distribution is shown in Fig. 6.
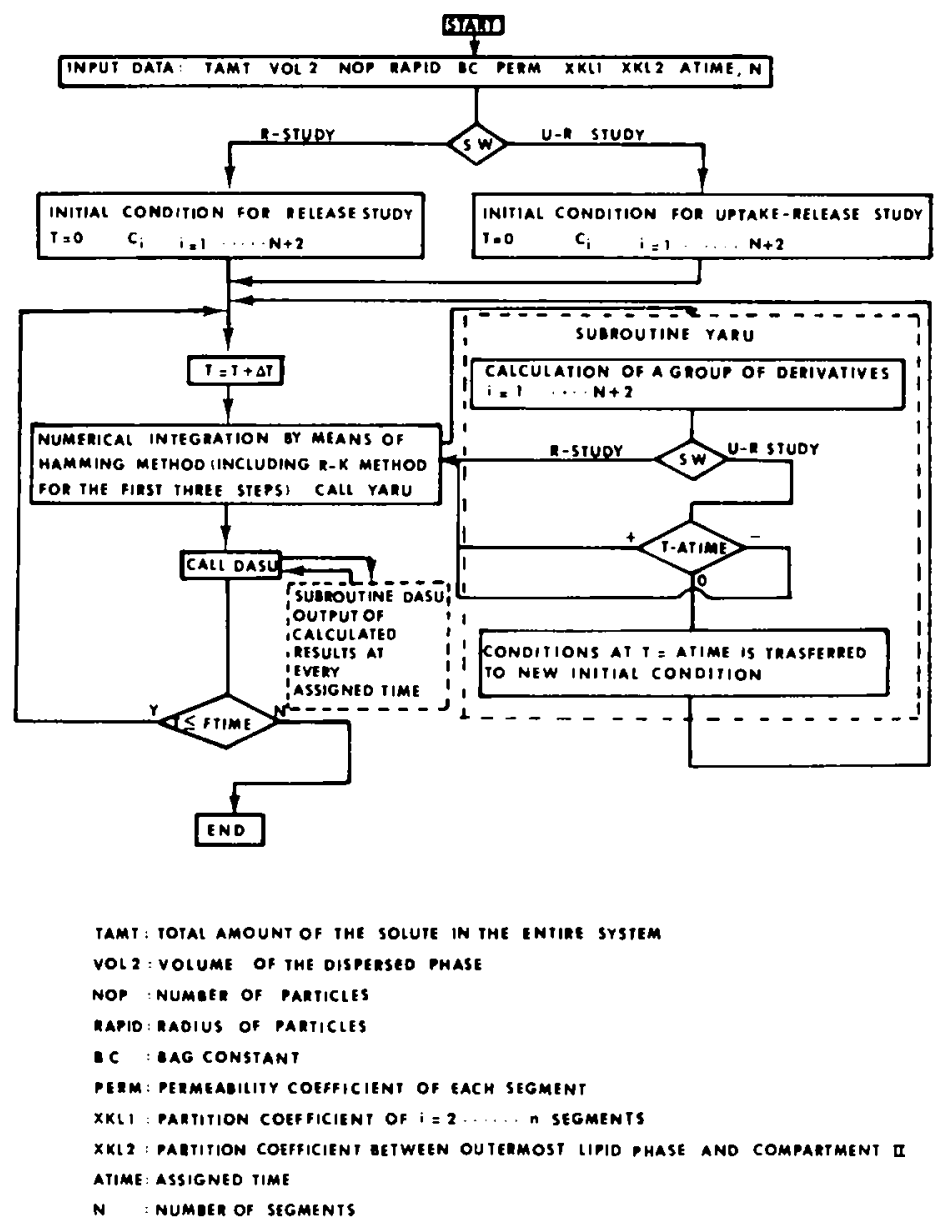

Fig. 6. Flow diagram used for the computations of concentration and amount distributions in the physical models for three different initial boundary conditions. 
As would be seen later, the initial slope of the solute transport would be mainly a function of the partition coefficient. So, the partition coefficient was determined by trying different values to fit the initial experimental points. Different permeability coefficients were then tried in an attempt to fit the theory with the experiment. The results of these computations for the release experiments are shown in Fig. 7 and compared to the experimental data. It is apparent that a reasonable fit of the experimental data with the theory cannot be obtained by trying different permeability coefficients.

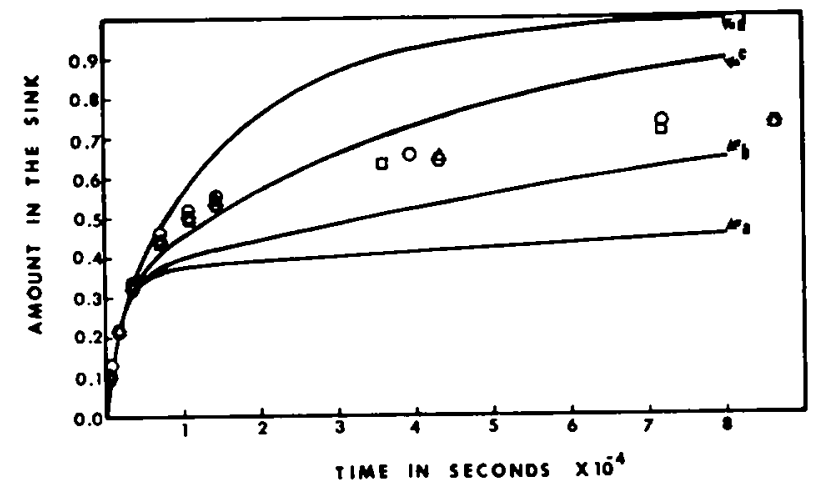

Fig. 7. Comparison of experimental data and results of computations using monosize-single membrane model. Symbols represent experimental data; curves represent results of computations: $p=2.666 \cdot 10^{-10}$ for Curve $a, p=1.2 \cdot 10^{-9}$ for Curve $b, p=4 \cdot 10^{-9}$ for Curve c, $p=1.2 \cdot 10^{-8}$ for Curve d.

\section{Multisize single membrane model}

In this physical model the assumption of monosize spherules is not made and the particle size distribution determined with the Coulter Counter is incorporated into the analysis. The other assumptions remain unchanged.

Considering all elements of the particle size distribution for the average solute concentration in the spherules Eqn I2 is obtained.

$$
C_{j, \mathrm{I}, \mathrm{t}}=\frac{V_{j, \mathrm{I}}\left(v_{\mathrm{a}}+v_{l} \cdot k\right)}{V_{j, \mathrm{I}}\left(v_{\mathrm{a}}+v_{l}\right)} \cdot C_{j, \mathrm{l}, \mathrm{a}}
$$

Here $V_{j, I}$ and $C_{j, I, s}$ are the total volume and the aqueous solute concentration of the spherules in $j$ th element of particle size distribution which is comprised of $j=I$ to $j=m$ size elements.

The rate at which solute is released from the spherules in the $j$ th element of the particle size distribution is given by Eqn $\mathrm{r} 3$.

$$
-V_{j, 1}\left(v_{\mathrm{a}}+v_{l} \cdot k\right) \cdot \frac{\mathrm{d} C_{j, 1, \mathrm{a}}}{\mathrm{d} t}=S_{j, 1} \cdot p\left(C_{j, 1, \mathrm{a}}-C_{\mathrm{ll}}\right)
$$

The total flux from Compartment $\mathrm{I}$ is then given by Eqn I4.

$$
G_{\mathrm{I}}=\sum_{j=1}^{m} S_{j, \mathrm{i}} \cdot p\left(C_{j, \mathrm{I}, \mathrm{a}}-C_{\mathrm{II}}\right)
$$


The expression for solute concentration in Compartment II is given by Eqn 15 .

$$
V_{\mathrm{II}} \cdot \frac{\mathrm{d} C_{\mathrm{II}}}{\mathrm{d} t}=\left[\sum_{j=1}^{m} S_{j, \mathrm{I}} \cdot p\left(C_{j, \mathrm{I}, \mathrm{a}}-C_{\mathrm{II}}\right)\right]-S_{\mathrm{b}} \cdot p_{\mathrm{b}} \cdot C_{\mathrm{II}}
$$

The rate of appearance of the solute in the sink is then given by Eqn II as before.

These equations were solved as outlined earlier adjusting first the partition coefficient to the initial rate data and then varying the permeability coefficient over a range of values. The results of these computations for the release experiments are given in Fig. 8. The comparisons between theory and experimental show that a reasonable agreement cannot be obtained simply by adjustment of the permeability coefficient.

The above analysis of monosize and multisize single membrane models strongly indicates that such release data cannot be handled by physical models which assume only a single membrane controlled process. In view of this, it was believed that physical models considering multiconcentric layers separating aqueous compartments should be investigated.

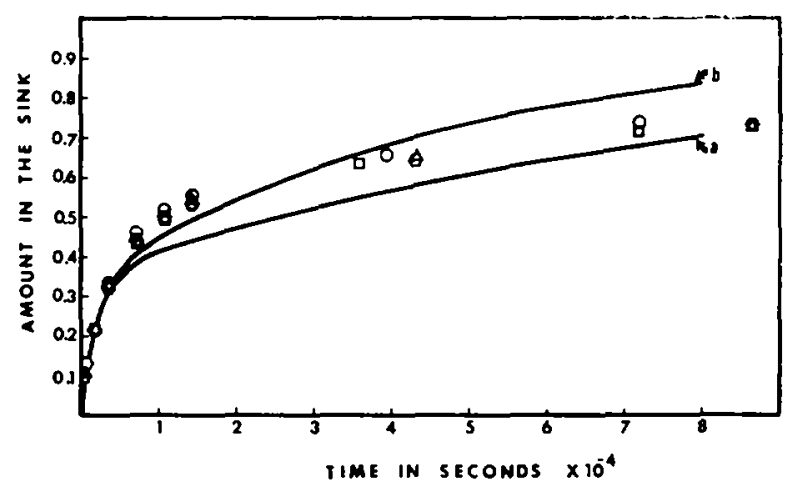

Fig. 8. Comparison of release experimental data and results of computation using the multisize single membrane model. Symbols represent experimental data; curves represent theoretical calculations : $p=2 \cdot 10^{-9}$ for Curve $a, p=4 \cdot 10^{-9}$ for Curve b.

\section{Monosize-multiconcentric layer model $r$}

As a first approximation, it is assumed here that all the spherules are of the same size. Fig. ga gives a schematic diagram of this model. A schematic cross section showing the division of Compartment I into segments is shown in Fig. 9b. In each spherule $i=\mathrm{I} \ldots n$ number of concentric layers (segments) of equal thickness are considered. Segment $I$ is defined as the innermost aqueous phase. Segments $2 \ldots n$ contain an aqueous phase and a lipid phase. The externalmost lipid phase is considered as part of Compartment II. The main barrier to solute transport is assumed to be the inner aqueous lipid interface. It is assumed that there is good mixing in both phases, so that there is no concentration gradient in each segment, neither in the lipid phase, nor in the aqueous phase. The partition coefficient, $k_{1}$, applies to the lipid in the $i=-2 \ldots n$ segments and the partition coefficient, $k_{2}$, refers to the outermost lipid phase and Compartment II. 


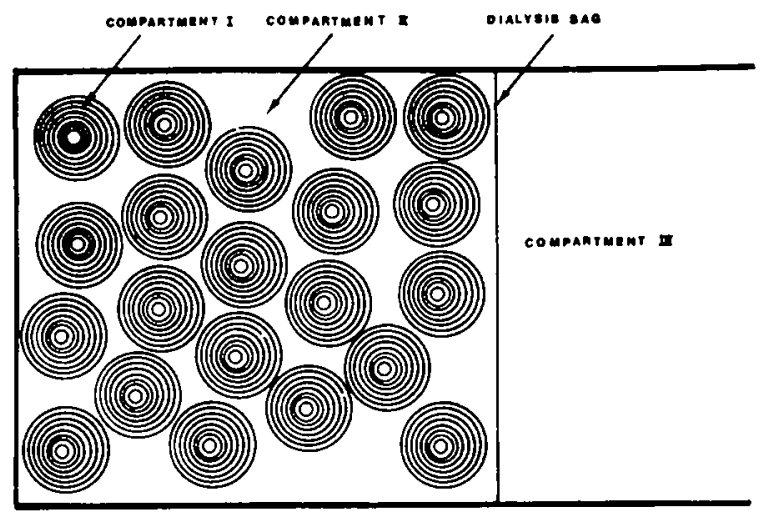

$|0|$

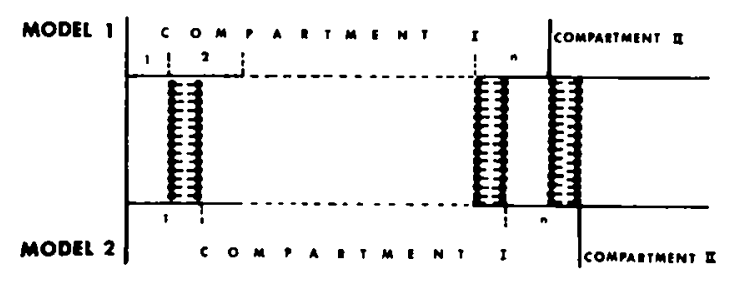

$|b|$

Fig. 9. (a) Schematic representation of monosize-multiconcentric layer model. (b) Schematic cross section of multiconcentric layer model showing the division of Compartment I into $i=1 \ldots n$ segments and the differences between Model $\mathbf{r}$ and Model 2.

Eqn 16 relates the average solution concentration to the aqueous and lipid contributions for the $i=2$ to the $i=n$th segment

$$
\begin{aligned}
& \left(V_{1} \cdot v_{l}+V_{2} \cdot v_{\mathrm{a}}\right) C_{2, t}=\left(V_{1} \cdot v_{l} \cdot k_{1}+V_{2} \cdot v_{\mathrm{a}}\right) C_{2, \mathrm{a}} \\
& \vdots \\
& \left(V_{n-1} \cdot v_{l}+V_{n} \cdot v_{\mathrm{a}}\right) C_{n, t}=\left(V_{n-1} \cdot v_{l} \cdot k_{1}+V_{n} \cdot v_{\mathrm{a}}\right) C_{n, \mathrm{a}} \\
& \left(V_{n} \cdot v_{l}+V_{\mathrm{II}}\right) C_{\mathrm{II}, t}=\left(V_{n} \cdot v_{l} \cdot k_{2}+V_{\mathrm{II}}\right) C_{\mathrm{II}, \mathrm{a}}
\end{aligned}
$$

The rates at which solute leaves Segment I and Segments $i=2 \ldots n$ are given by the set of Eqn I7.

$$
\begin{aligned}
& -V_{1} \cdot v_{\mathrm{a}} \cdot \frac{\mathrm{d} C_{1, \mathrm{a}}}{\mathrm{d} t}=S_{1} \cdot p\left(C_{1, \mathrm{a}}-C_{2, \mathrm{a}}\right) \\
& \left(V_{1} \cdot v_{l} \cdot k_{1}+V_{2} \cdot v_{\mathrm{a}}\right) \frac{\mathrm{d} C_{2, \mathrm{a}}}{\mathrm{d} t}=S_{1} \cdot p\left(C_{1, \mathrm{a}}-C_{2, \mathrm{a}}\right)-S_{2} \cdot p\left(C_{2, \mathrm{a}}-C_{3, \mathrm{a}}\right) \\
& \vdots \\
& \left(V_{n-1} \cdot v_{l} \cdot k_{1}+V_{n} \cdot v_{a}\right) \frac{\mathrm{d} C_{n, \mathrm{a}}}{\mathrm{d} t}=S_{n-1} \cdot p\left(C_{n-1, \mathrm{a}}-C_{n, \mathrm{a}}\right)-S_{n} \cdot p\left(C_{n, \mathrm{a}}-C_{\mathrm{II,a}}\right)
\end{aligned}
$$


The rate of appearance of the solute in Compartment II is given by Eqn I8.

$$
\left(V_{n} \cdot v_{l} \cdot k_{2}+V_{\mathrm{Il}}\right) \frac{\mathrm{d} C_{\mathrm{II}, \mathrm{a}}}{\mathrm{d} t}=S_{n} \cdot p\left(C_{n, \mathrm{a}}-C_{\mathrm{II}, \mathrm{a}}\right)-S_{\mathrm{b}} \cdot p_{\mathrm{b}} \cdot C_{\mathrm{II}, \mathrm{a}}
$$

The rate expression for the amount of solute in the sink is again given by Eqn II.

Eqn II and Eqns I6-I 8 were solved as outlined earlier (see Fig. 6) utilizing a "best" set of parameter values which will be discussed below. Figs $2-4$ give the

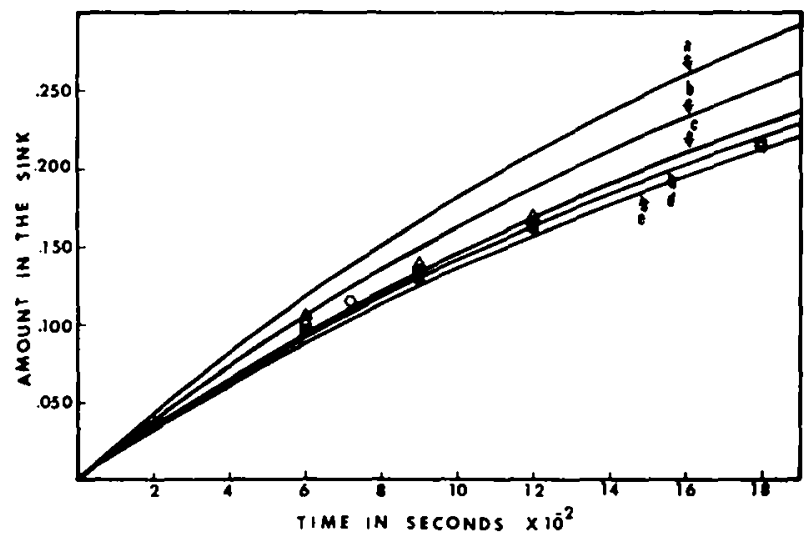

Fig. Io. Determination of partition coefficients, $k_{1}$ and $k_{2}$, from the initial transport rate for the release experiments using Eqn $I I$ and Eqns 16 to 18 . Symbols represent experimental data, curves represent different partition coefficient values used in the computations: $k_{1}=k_{2}=I_{5}$ for Curve $\mathrm{a} ; k_{1}=k_{2}=19$ for Curve $\mathrm{b} ; k_{1}=k_{2}=23$ for Curve $\mathrm{c} ; k_{1}=k_{2}=25$ for Curve d; $k_{1}=k_{2}=27$ for Curve e; other parameters were taken from Table II.

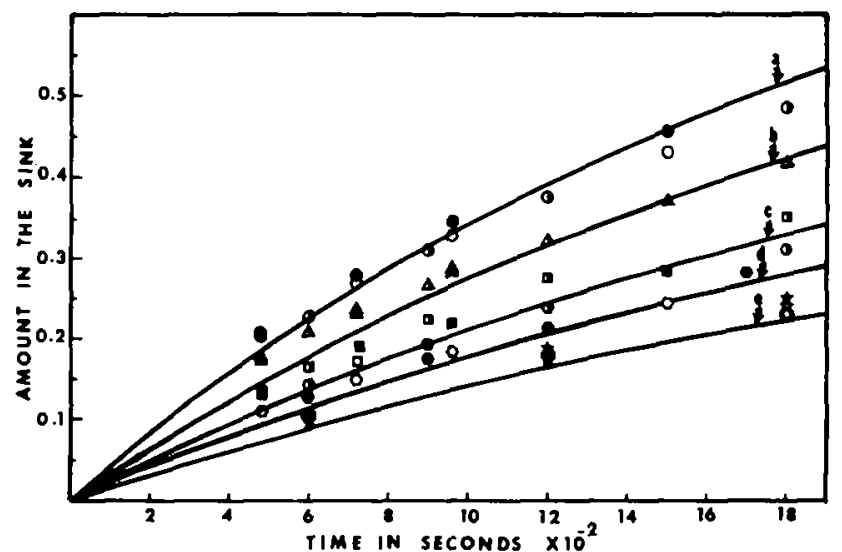

Fig. 1 I. Comparisons of the experimental initial release rate data, obtained from the second and the third initial boundary condition cases with the computation results using the monosizemulticoncentric layer Model I using the parameter values given in Table II. Curve a represents theory for the o-h uptake case, circles are the experimental o-h uptake case; Curve b represents theory for the 2 -h uptake case, triangles are the experimental $2-h$ uptake case; Curve c represents theory for the Io-h uptake case, squares are the 10-h uptake experimental points for dispersion systems prepared from batch $I$, batch 2 and commercial batch of lecithin, respectively; Curve $d$ represents theory for $24^{\text {-h }}$ uptake case, hexagonals represent experimental points for dispersion systems prepared from batch 1 , batch 2 , and commercial batch of lecithin respectively; Curve $\mathrm{e}$ represents theory for the dilution-release experimental case and the corresponding symbols (stars) are the experimental data for this situation. 
comparison between these theoretical computations and the three different types of experiments. In Fig. 2 the direct-release results are compared, and in Figs 3 and 4 the dilution-release and the uptake-release results are compared with the theoretical computations. Figs Io and II give some of the early time results compared to theory on an expanded scale.

The generally good agreement found between all of the experiments and this model employing a single set of parameters suggests that this model may be a reasonably good one for quantitatively characterizing the transport behavior in the liposome dispersion systems.

Convergence of theoretical release curves. For the multiconcentric layer model, the choice of the value for the permeability coefficient, $p$, depends upon both the radius, $r$, of the spherules and the number $n$, of segments used in the calculations according to the relationship:

$$
p=\frac{P \cdot n}{r}
$$

Here, $P$ could be regarded as the effective bulk permeability coefficient, when the spherule is treated as a homogeneous sphere. Fig. $\mathrm{r} 2$ shows the convergence behavior of the theoretical curves as $n$ is increased at constant $P$. The dotted line represents the extrapolated release curve when $n$ is approaching infinity. Note that when $n=45$, which was the value used in the calculations given in Fig. 2 , the curve is about $2 \%$ higher than that for $n \rightarrow \infty$ case. The relationship defined in Eqn r 9 points out that in the absence of precise information about the actual number of concentric layers in the lecithin spherules, the effective bulk permeability coefficients, $P$, could be a very useful parameter for quantitating the permeability behavior of the liposomes. It is therefore proposed that the best $P$ values be determined in such cases at sufficiently large $n$ values.

Convergence of theoretical uptake-release curves. For uptake-release experiments Eqn 19 could also be used to study the convergence of release curves by trying different $n$ values, keeping $P$ constant. The results of the theoretical calculations for

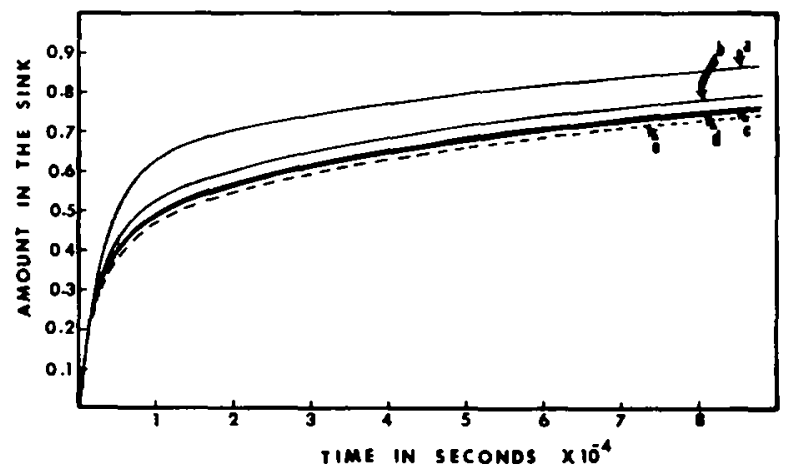

Fig. 12. Calculations using the monosize multiconcentric Model I showing the convergence of theoretical release curves for sufficiently large $n$ (Eqn 19). Curve a, $n=5$; Curve $b, n=15$; Curve c, $n=30$; Curve $d, n=45$. The dotted Curve e, corresponds to the case when $n$ is extrapolated to infinity. $p / n=\left(2.666 \cdot 10^{-10}\right)$ for all calculations, and other parameters taken from Table II, 
the 2-h uptake case is given in Fig. I3. As can be seen, the curves appear to be converged by $n=45$.

Sensitivity of the method to $P$. Taking the situation when $n$ is sufficiently large, calculations were carried out to determine the sensitivity of the method to effective bulk permeability coefficient, $P$. The results in which $P$ was the only variable are presented in Fig. I4.

It is important to note that the initial part of the curves is not sensitive to $P$. However, the slopes of the later time portions of the curves are strongly dependent upon $P$.

Partition coefficients $\left(k_{1}, k_{2}\right)$. The initial slopes (see Fig. Io) of the solute release rate is mainly a function of the partition coefficients, provided $n$ is sufficiently large. The results of the computations, when the partition coefficients were the only variables, are given in Figs Io and $\mathrm{r}_{5}$. It is noteworthy that, while the partition coefficients alter the position of the curves relative to each other, the slopes of the later time portions of the release curves remain relatively constant.

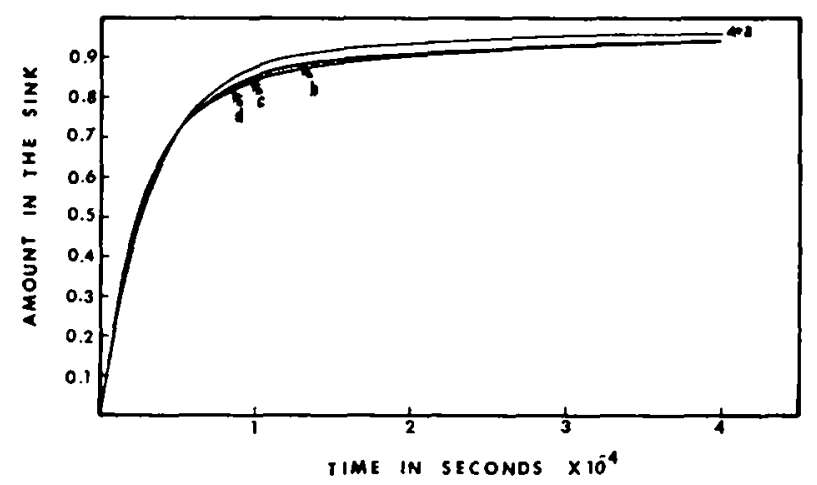

Fig. I3. Calculations for the third initial boundary condition case with a $2 \mathrm{~h}$ uptake using monosize-multiconcentric Model $I$. The curves show the convergence of the theoretical release for sufficiently large $n$ (Eqn 19); Curve a, $n=5$; Curve b, $n=15$; Curve c, $n=30$; Curve d, $n=45$, $p / n=\left(2.666 \cdot 10^{-10}\right)$ and the other parameter values taken from Table II.

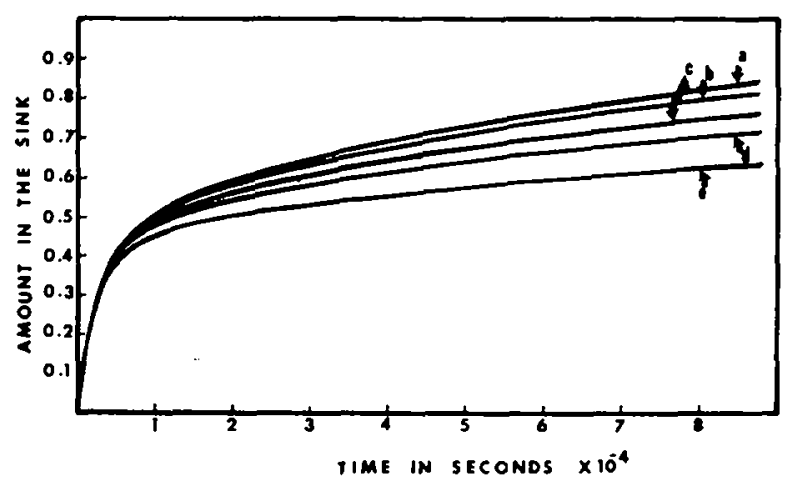

Fig. I 4. Calculations using monosize multiconcentric Model I showing the effect of the effective bulk permeability coefficient on release curve. Curve a, $P=2.435^{\circ} \cdot 10^{-10}$; Curve $\mathrm{b}, P=$

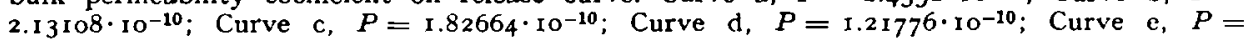
$6.0888 \cdot 10^{-11}$. Other parameter values taken from Table II. 
Experimental bag constant. Slight variations in bag constant are expected from experiment to experiment. Computations were, therefore, carried out in which the bag constant was varied \pm Io $\%$. All other parameters were kept constant. The results of these calculations are given in Fig. I6. It can be seen that such variations in the bag constant would only affect the initial part of the curve.

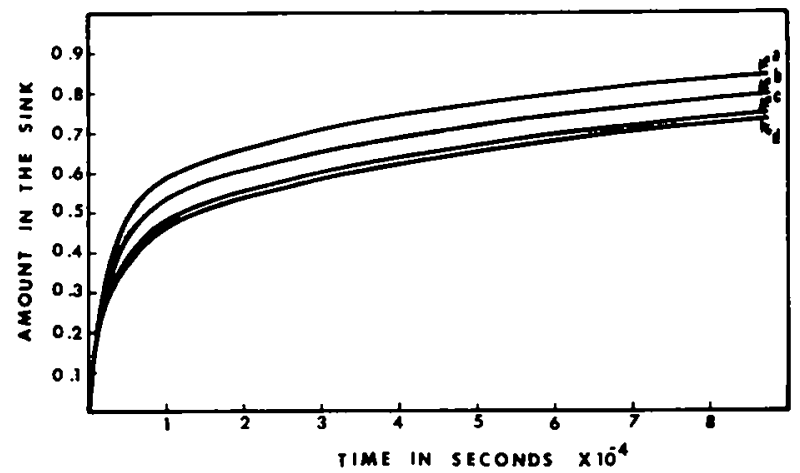

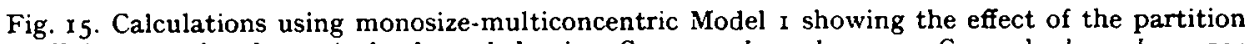
coefficient on the theoretical release behavior. Curve $\mathrm{a}, k_{1}=k_{2}=\mathrm{I} 5$; Curve $\mathrm{b}, k_{1}=k_{2}=\mathrm{I} 9$; Curve c, $k_{1}=k_{2}=25 ;$ Curve d, $k_{1}=k_{2}=27$.

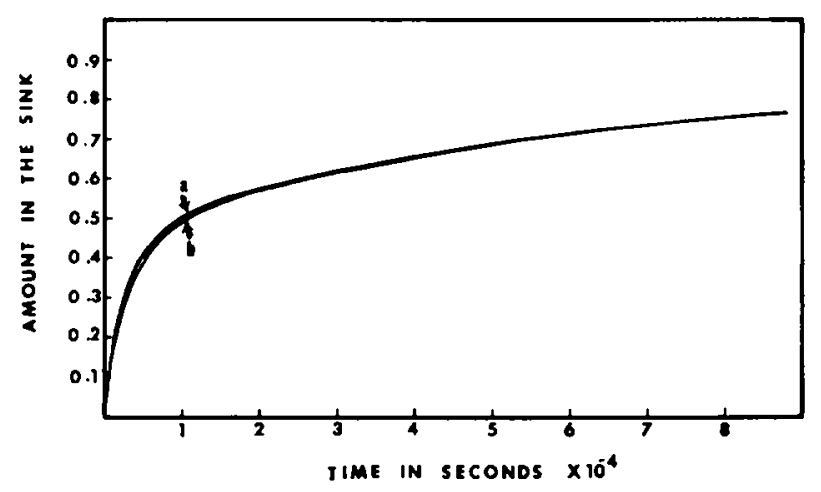

Fig. 16. Calculations using monosize-multiconcentric Model I showing the effect of the bag constant on theoretical release rate. Curve $a,+10 \%$ deviation; Curve $b,-10 \%$ deviation from experimentally determined bag constant value. Other parameters taken from Table II.

Influence of the spherule volume. The volume of the entrapped aqueous solution was varied in the calculations, keeping other parameters constant, in order to study the sensitivity of the calculations to the quantity. Fig. $I 7$ gives the results of these computations which show that a $20 \%$ spherule volume uncertainty has a relatively small effect on the calculations.

Mean surface and mean volume radii. The calculated values of the mean surface and mean volume radii were different for the same particle size distribution (Table I). Fig. I 8 gives the results of the computations using the two different radii values keeping all other quantities constant. The effect is quite small and on this basis either, mean surface radius, or mean volume radius could have been used.

Partition coefficient, $k_{2}$. In the monosize-multiconcentric Model I two partition 
coefficients were defined. The reason for this was that the external most lipid phase might be expected to behave differently than the lipid in the inner layers. Also the entrapped aqueous solution might be expected to behave differently than the bulk aqueous solution in Compartment II as far as partitioning of solutes are concerned.

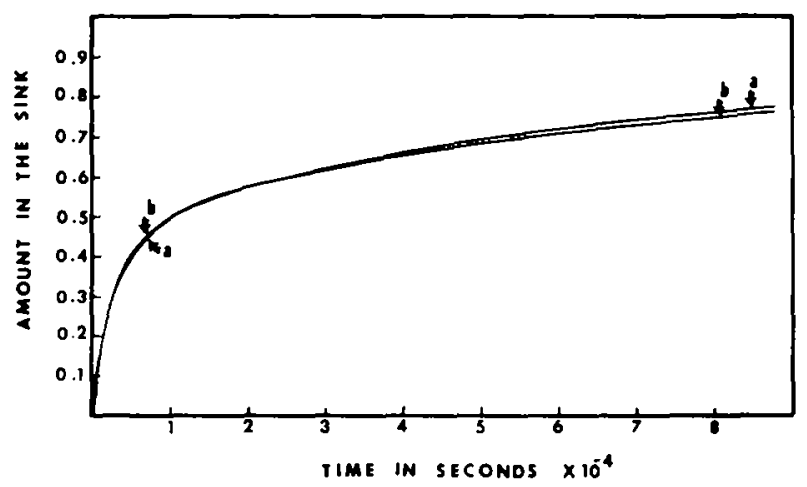

Fig. 17. Calculations using monosize-multiconcentric Model $I$ showing the effects of uncertaintie in volume of Compartment $\mathrm{I}$ on the theoretical release. Curve $\mathrm{a}, V_{\mathrm{I}}=1.15 \mathrm{ml}$; Curve $\mathrm{b}, V_{\mathrm{I}}=$ $0.95 \mathrm{ml}$.

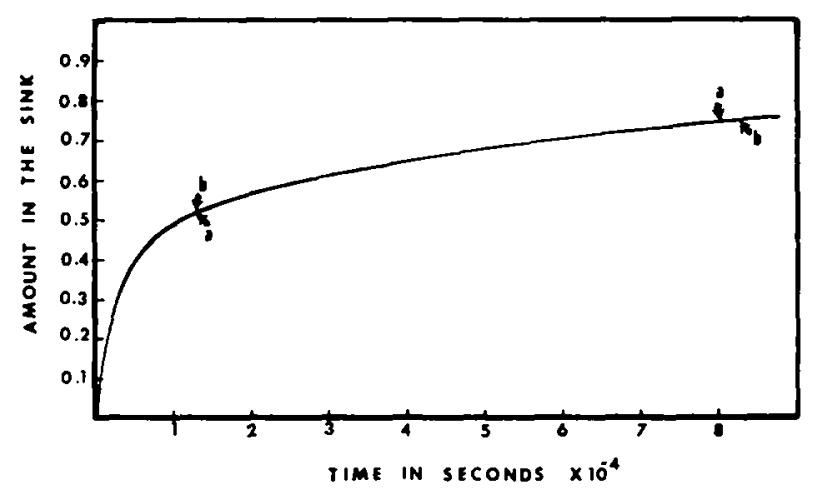

Fig. 18. Calculations using monosize-multiconcentric Model I comparing the release results using the mean surface radius with those obtained using the mean volume radius. Curve a, mean volume radius; Curve $b$, mean surface radius.

Fig. Ig shows the results of the computations in which $k_{2}$ was the only variable. As can be seen the influence of the choice of $k_{2}$ over a reasonable range is quite small when $n$ is large. The effect of $k_{2}$ becomes more important as $n$ decreases. If an extremely large value for $k_{2}$ were to be appropriate, significant negative deviations of the experiment from theory (Model I) should have been observed in the results shown in Fig. II for the early time data in the uptake-release studies. However, the deviations were small and, if anything, were in the opposite direction.

\section{Monosize-multiconcentric layer Model 2}

In the preceding discussion it was shown that the choice of $k_{2} \simeq k_{1}$ was reasonable and the fit of the experimental data to theory was relatively insensitive 
to $k_{2}$ (see Fig. Ig) when $n$ was large. This essentially means that adsorption or binding of the solute in the outermost layer is no more important than that in the interior lipids.

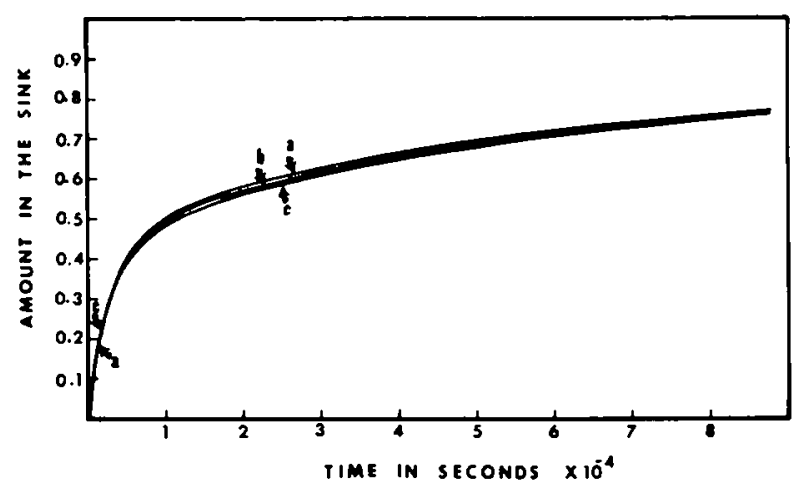

Fig. 19. Calculations using monosize-multiconcentric layer Model I showing the effect of $k_{2}$ on theoretical release curve. Curve $\mathrm{a}, k_{2}=2$; Curve b, $k_{2}=23$; Curve $\mathrm{c}, k_{2}=4^{0}$. Other parameter values were taken from Table II.

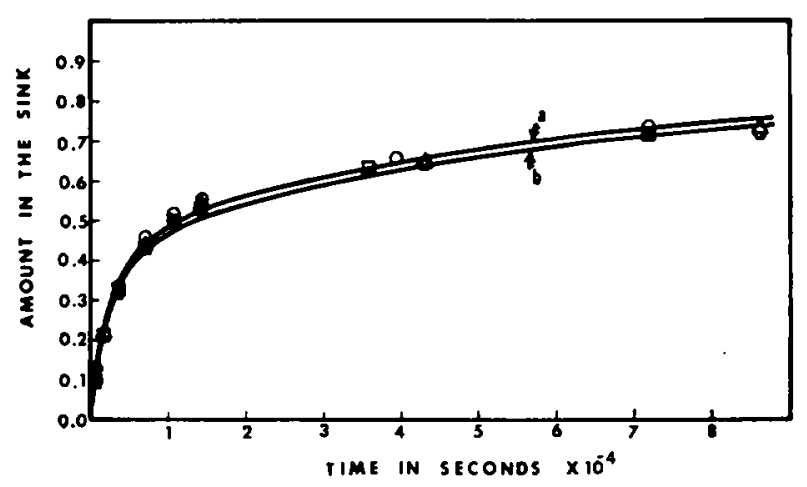

Fig. 20. Comparison of experimental data and results of computations using monosize-multiconcentric layer Model 2 for the release experiment. Symbols represent experimental data, curves represent results of computations: for Curve $\mathrm{a}, k=2 \mathrm{I}$; for Curve $\mathrm{b}, k=23$. Other parameter values taken from Table II.

An alternative way of examining this question is to investigate a model in which the last lipid layer is treated as the same as the other lipid layers in the spherule. Consequently, Model 2 requires only a single $k$ value. Fig. $9 \mathrm{~b}$ shows a schematic cross section of Model 2 and division of Compartment I into segments. In this case, in contrast to Model I, the outermost lipid layer is "inside" the spherule. The location of the barrier to solute transport is assumed to be at the outer water-lipid interface for each segment. Other assumptions remain the same as those used in Model r. Equations analogous to equations given under Model I may be deduced and solved. Fig. 20 presents the best fit results of Model 2 with the experimental data. It can be seen that the same good fit was obtained using the same parameter values given in Table II except for the slightly smaller $k$ value was required. 
TABLE II

THE INPUT DATA LSED IN THE CALCULATIONS FOR THE MONOSIZE-MULTICONCENTRIC MODEL I AND MONOSIZE-MLLTICONCENTRIC MODEL 2

\begin{tabular}{|c|c|c|c|c|c|c|c|c|}
\hline & \multirow[t]{2}{*}{$\begin{array}{l}V_{1} \\
(m l)\end{array}$} & \multirow[t]{2}{*}{$n$} & \multirow[t]{2}{*}{$\begin{array}{l}p \times I 0^{8} \\
\left(\mathrm{~cm} \cdot \mathrm{s}^{-1}\right)\end{array}$} & \multirow[t]{2}{*}{$\begin{array}{l}p_{b} \cdot S_{b} \times 10^{3} \\
\left(\mathrm{~cm}^{3} \cdot \mathrm{s}^{-1}\right)\end{array}$} & \multicolumn{3}{|c|}{$\begin{array}{l}\text { Partition } \\
\text { coefficient }\end{array}$} & \multirow{2}{*}{$\begin{array}{l}\text { Mean } \\
\text { surface radius } \\
(\mu \mathrm{m})\end{array}$} \\
\hline & & & & & & $k$ & $k_{2}$ & \\
\hline $\begin{array}{l}\text { Monosize- } \\
\text { multiconcentric } \\
\text { layer Model I }\end{array}$ & I.05 & 45 & 1.2 & 1.919 & 23 & & 23 & 0.685 \\
\hline $\begin{array}{l}\text { M rosize- } \\
\text { multiconcentric } \\
\text { layer Model } 2\end{array}$ & I.05 & 45 & I. 2 & I.919 & & $2 I$ & & 0.685 \\
\hline
\end{tabular}

\section{Multisize-multiconcentric layer models}

A major assumption in the two models described above was that the spherules were all of the same size. Therefore, it is important to show that particle size distribution effects would be expected, to be negligible or small. An estimate of the particle size distribution effect was made by taking the first nine elements of Table I, i.e.

TABLE III

THE INPUT DATA USED IN THE CALCULATIONS FOR THE MULTISIZE-MULTICONCENTRIC MODELS

\begin{tabular}{|c|c|c|c|c|c|c|}
\hline \multirow{3}{*}{$\begin{array}{l}\text { Mean } \\
\text { surface radius } \\
(\mu m)\end{array}$} & \multirow{3}{*}{$\begin{array}{l}\text { Total No. } \\
\text { of particles } \\
\times I O^{-10}\end{array}$} & \multirow{3}{*}{$\begin{array}{l}\text { No. of } \\
\text { segments }\end{array}$} & \multirow{3}{*}{$\begin{array}{l}p \times 10^{9} \\
\left(\mathrm{~cm} \cdot \mathrm{s}^{-1}\right)\end{array}$} & \multicolumn{3}{|c|}{ Partition coefficient } \\
\hline & & & & \multicolumn{2}{|c|}{ Model I } & \multirow{2}{*}{$\frac{\text { Model } 2}{k}$} \\
\hline & & & & $k_{1}$ & $k_{2}$ & \\
\hline 0.6085 & $7^{8.10}$ & I 5 & $4 \cdot 5$ & 23 & 23 & $2 I$ \\
\hline 0.93336 & 4.80 & 23 & $4 \cdot 5$ & 23 & 23 & 21 \\
\hline 1.2229 & 1.95 & 30 & $4 \cdot 5$ & 23 & 23 & $2 \mathrm{I}$ \\
\hline
\end{tabular}

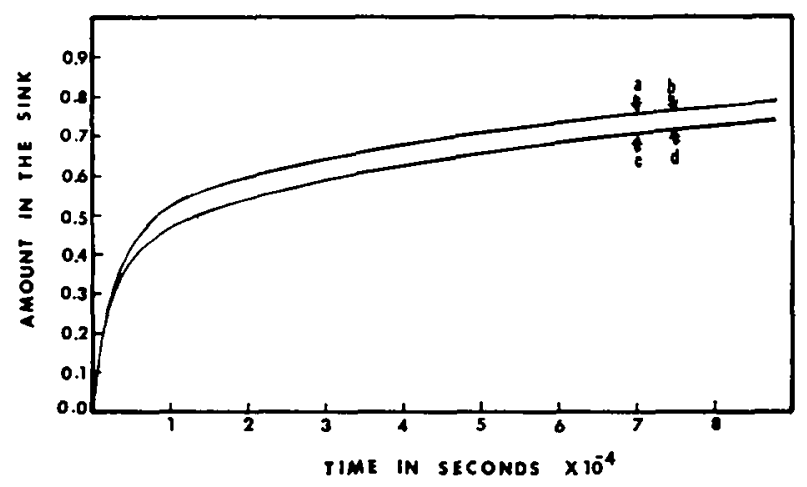

Fig. 21 . Comparison between the calculated release curves using the monosize multiconcentric layer models and multisize-multiconcentric models. Curve a, monosize-multiconcentric Model I; Curve b, multisize-multiconcentric layer Model I; Curve c, multisize-multicon centric layer Model 2 Curve d, monosize-multiconcentric layer Model 2. 
particle size distribution between 0.52 and $1.49 \mu \mathrm{m}$ radius. The particles in the range represent about $85 \%$ of the total volume of the spherules. The computations were further simplified by dividing the nine elements into three sections for which the mean surface radii were calculated. The number of segments were then estimated for the three sizes (see Table III). The basic equations for this situation would involve a combination of equations of the type used for the multisize-single membrane model and the monosize multiconcentric layer Model I or Model 2.

Fig. 21 gives the theoretical curves for the multisize-multiconcentric layer models based upon the input data given in Table III. These are compared to the monosize-multiconcentric layer models theoretical results. As can be seen the differences between the monosize and multisize models are very small. Therefore, the approximation of neglecting the distribution of particle sizes is a good one. These results further support the use of the monosize-multiconcentric layer Model I or Model 2 for determining effective bulk permeablity coefficients in the liposome dispersion model membrane systems.

\section{KEY TO THE SYMBOLS USED IN THE TEXT}

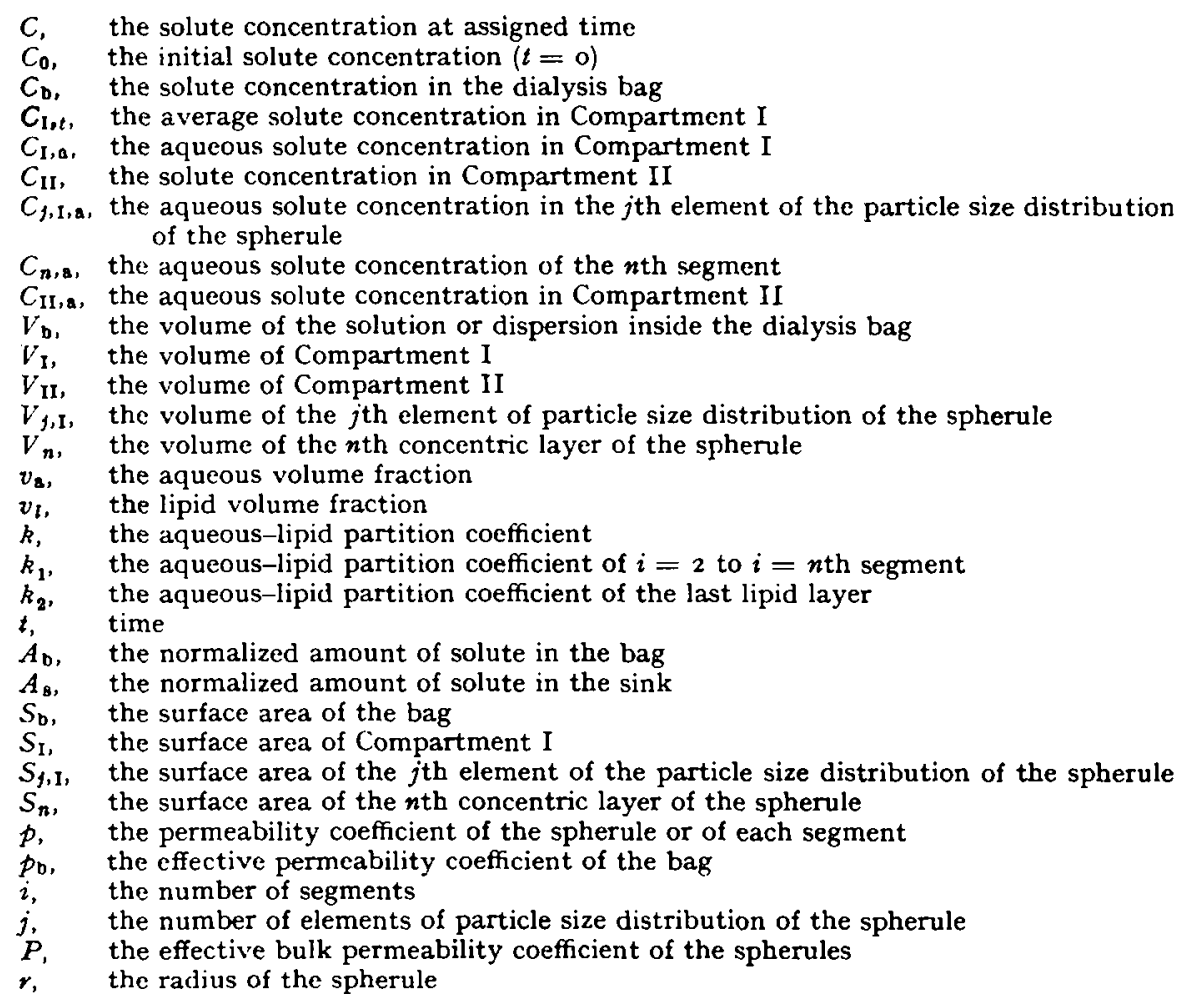

\section{ACKNOWLEDGEMENTS}

This investigation was supported by the National Institute of Dental Research Training Grant, DE-00204 and by National Institute of General Medical Sciences Grant GM-I3368. 


\section{REFERENCES}

I J. F. Danielli and H. A. Davson, J. Cell. Comp. Physiol., 5 (1935) 495.

2 J. D. Robertson, N.Y. Acad. Sci., 137 (I966) 42 I.

3 W. Bartley, in R. M. C. Dawson and D. M. Rhodes, Metabolism and Physiological Significance of Lipids, John Wiley and Sons, London, I964, p. 379.

4 A. D. Bangham, M. M. Standish and J. C. Watkins, J. Mol. Biol., I 3 (I965) 238.

5 W. Stoeckenius, J. Cell Biol., 12 (1962) 221.

6 A. D. Bangham and R. W. Horne, J. Mol. Biol., 8 (1964) 660.

7 K. J. Palmer and F. O. Schmitt, J. Cell. Comp. Physiol., 17 (194 I) 385.

8 V. Luzzati and F. Husson, $J$. Cell Biol., 12 (1962) 207.

9 D. Papahadjopoulos and N. Miller, Biochim. Biophys. Acta, 135 (1967)624.

Io A. Frey-Wyssling, Submicroscopic Morphology of Protoplasm, Elsevier, Amsterdam, 1953, p. 82.

I I D. G. Dervichian, Prog. Biophys. Mol. Biol., I 4 (I964) 265.

12 G. Weissmann and G. Sessa, J. Biol. Chem., 242 (1966) 616.

I 3 G. Sessa and G. Weissmann, Biochim. Biophys. Acta, 135 (1967) 416 .

14 H. Van Zutphen, L. L. M. Van Deenen and S. C. Kinskey, Biochim. Biophys. Res. Commun., 22 (1966) 393.

I5 S. C. Kinskey, S. A. Luse and L. L. M. Van Deenen, Fed. Proc., 25 (1966) 1503.

I6 S. M. Johnson and A. D. Bangham, Biochim. Biophys. Acta, I93 (1969) 82 .

I7 J. Shah, 1). Papahadjopoulos and C. E. Wenner, Biochim. Biophys. Acta, I96 (1970) Io.

I 8 A. D. Bangham, M. M. Standish and G. Weissmann, J. Mol. Biol., I3 (1965) 253.

I9 $G$. Sessa and G. Weissmann, Biochim. Biophys. Acta, I 50 (1968) 173.

20 A. D. Bangham, M. M. Standish and N. Miller, Nature, 208 (1965) I 295.

2 I S. M. Johnson and A. D. Bangham, Biochim. Biophys. Acta, 193 (1969) 92.

22 D. Papahadjopoulos, Biochim. Biophys. Acta, 2 I I (I970) 467.

23 G. Weissmann, G. Sessa and S. Weissmann, Nature, 208 (I965) 649.

24 G. Weissmann, G. Sessa and S. Weissmann, Biochem. Pharm., I 5 (1966) 1537.

25 D. Papahadjopoulos and A. D. Bangham, Biochim. Biophys. Acta, I 26 (1966) I 85 .

26 G. B. Ansell and J. N. Hawthorne, Phospholipids, Elsevier Publishing Company, New York, I 964 , pp. 88-9 I.

27 D. X. Rhodes and C. H. Lea, Biochem. J., 65 (1957) 526.

28 J. Hirsch and E. H. Ahrens, Jr, J. Biol. Chem., 233 (I958) 3 I I.

29 G. V. Marinetti, J. Lipid Res., 3 (I962) I.

3o H. K. Mangold and D. C. Malins, J. Am. Oil Chem. Soc., 37 (1960) 383.

3 I R. P. A. Sims and J. A. G. Larose, J. Am. Oil Chem. Soc., 39 (I962) 232.

32 Z. T. Chowhan, Model Transport Studies Utilizing Lecithin Spherules, Ph. D. Thesis, University of Michigan, Ann Arbor, Mich., I972.

Biochim. Biophys. Acta, $266\left(197^{2}\right) 320-34^{2}$ 